\title{
Investigation of the role of the C-terminus of Bax and of tc-Bid on Bax interaction with yeast mitochondria
}

\author{
Muriel Priault ${ }^{1,4}$, Pierre-François Cartron ${ }^{2}$, \\ Nadine Camougrand ${ }^{1}$, Bruno Antonsson ${ }^{3}$, \\ François M. Vallette ${ }^{2}$ and Stéphen Manon ${ }^{\star, 1}$ \\ 1 UMR 5095 CNRS/Université de Bordeaux 2, 1 Rue Camille Saint-Saëns, \\ F-33077 Bordeaux, France \\ 2 UR 419 INSERM/Université de Nantes, 9 Quai Moncousu, F-44035 Nantes, \\ France \\ 3 Serono Pharmaceutical Research Institute, 14 Chemin des Aulx, CH-1228 \\ Plan-les-Ouates, Switzerland \\ ${ }^{4}$ Current address: Département de Biologie Cellulaire, Sciences III, \\ 30 Quai Ernest Ansermet, CH-1211 Genève 4, Switzerland \\ * Corresponding author: S. Manon, UMR 5095 CNRS/Université de Bordeaux 2, \\ 1 Rue Camille Saint-Saëns, F-33077 Bordeaux cedex, France \\ Tel: + 33-556-99-90-45; Fax: + 33-556-99-90-51; \\ E-mail: manon@ibgc.u-bordeaux2.fr
}

Received 12.12.02; revised 03.1.03; accepted 04.1.03

Edited by S Roy

\section{Abstract}

Because of structural homology with the transmembrane domain of Bcl-2, the proapoptotic protein Bax has been proposed to be anchored to the outer membrane of mitochondria through its carboxy-terminal end (CT). We took advantage of the absence of Bcl-2 family members in yeast to further investigate the role of Bax CT in its mitochondrial association and function. The complete deletion or the addition of a C-terminal c-myc tag as well as the replacement of $\mathrm{CT}$ by a random coiled sequence enhanced membrane insertion of Bax. It has previously been suggested that conformational change in the $\mathrm{N}$-terminal end of Bax would allow the C-terminal end to play its anchoring function. We found that a mutant truncated in both $\mathrm{N}$ - and $\mathrm{C}$-termini still exhibited a strong binding activity to mitochondria. In mammals, Bax interaction with the caspase-8-generated truncated form of Bid (tc-Bid) is believed to promote a conformational change necessary for the insertion of Bax into mitochondria. We coexpressed Bax and tc-Bid in yeast and found that native Bax functions are not stimulated by tc-Bid, whereas functions of an active variant with a modified CT are. We propose that Bax CT has to undergo a conformational change to allow the insertion of Bax in mitochondria but, contrary to current views, is not a bona fide membrane anchor. Cell Death and Differentiation (2003) 10, 1068-1077. doi:10.1038/ sj.cdd. 4401270

Keywords: apoptosis, Bax; Bid; addressing; cytochrome $c$ release; yeast mitochondria

\begin{abstract}
Abbreviations: CT, C-terminal $\alpha$-helix; DPMS, dolichol-phosphate mannose synthase; MAC, mitochondrial apoptosis-induced channel; PGK, phosphoglycerate kinase; PVDF, polyvinyl difluoride; SDS-PAGE, sodium dodecyl sulphate-polyacrylamide gel electrophoresis; TCA, trichloroacetic acid
\end{abstract}

\section{Introduction}

Apoptosis, the best described type of programmed cell death, is a highly regulated phenomenon, and is under the control of numerous proteins, among which stand proteins of the $\mathrm{Bcl}-2$ family. ${ }^{1}$ Members of the Bcl-2 family are either pro- or antiapoptotic, and may exhibit a total or partial mitochondrial localization. ${ }^{2}$ Indeed, one of their main targets is mitochondria, where they control the release of apoptogenic factors from mitochondria to the cytosol. ${ }^{3}$ One of the most crucial steps in the implementation of apoptosis is the translocation, from cytosol to the mitochondrial outer membrane, of proapoptotic protein Bax. ${ }^{4,5}$ Bax is a relatively hydrophilic protein and its translocation and insertion into the mitochondrial outer membrane following apoptosis induction probably requires profound conformational changes. ${ }^{6}$

The 3D structure of Bax strongly resembles that of antiapoptotic members of the family, such as Bcl-2 or Bcl- $\mathrm{x}_{\mathrm{L}}{ }^{7}$ The mitochondrial localization of $\mathrm{Bcl}-2$ and $\mathrm{Bcl}-\mathrm{x}_{\mathrm{L}}$ is driven by their C-terminal $\alpha$-helix, which play the role of anchors spanning the mitochondrial outer membrane (as well as other intracellular membranes); actually, suppression of this $\alpha$-helix in antiapoptotic members of the Bcl-2 family impairs membrane localization and function both in yeast ${ }^{8-10}$ and mammalian cells. ${ }^{11-12}$

The anchoring function of the C-terminal $\alpha$-helix of proapoptotic Bax (Bax CT) is far less clear. Bax does not spontaneously interact with mitochondria, and when isolated from the rest of the protein, the CT does not behave like a membrane anchor, ${ }^{13,14}$ despite the fact that peptides derived from this sequence can disrupt the organization of lipid bilayers. ${ }^{15}$ Goping et al. ${ }^{16}$ observed that suppression of the $\mathrm{N}$ terminal end of Bax increased its insertion into the mitochondrial outer membrane and proposed that this $\mathrm{N}$-terminal part of the protein interacts with the C-terminal anchoring sequence, thus interfering with the targeting of Bax to mitochondria, and accounting for its withholding in the cytosol. Wood and Newcomb ${ }^{17}$ as well as Cartron et al. ${ }^{18}$ confirmed the positive effect of the $\mathrm{N}$-terminus deletion on binding to mitochondria, but Cartron et al. ${ }^{18}$ further reported that a variant deprived of both $\mathrm{N}$ - and $\mathrm{C}$-terminal ends exhibited a stronger binding to mitochondria than the single $\mathrm{N}$-terminusdeleted variant. In addition, and in disfavour with an anchoring function of the C-terminal end, a Bax variant only deprived of its C-terminal end still interacts with mitochondria and exhibits a killing function, both in yeast ${ }^{9-10}$ and in mammalian cells. ${ }^{13}$ Consequently, the consensus about a conformational change 
involving both $\mathrm{N}$ - and $\mathrm{C}$ - terminal ends of Bax and leading to its insertion into the mitochondrial outer membrane is still challenged by the fact that the respective function of these domains regarding Bax addressing remains unclear.

In the present paper, we re-evaluated the function of the Cterminal end of Bax by using the yeast system, which allows one to express Bax variants, independently of the presence of endogenous Bax and other Bcl-2 family members. Our data show that the C-terminus of Bax is not a membrane anchor but, on the contrary, that alterations that mimic a conformational change of the $\mathrm{C}$-terminus promote Bax/mitochondria interaction and further activation, independently of the presence of the $\mathrm{N}$-terminus. We further extended these studies by co-expressing Bid or its activated truncated form tcBid with active or inactive variants of Bax in yeast as tc-Bid has been proposed to be required for Bax to acquire its active conformation. ${ }^{19-21}$ We showed that tc-Bid stimulates the function of an activated Bax with a CT variant, but is not sufficient to activate Bax with a wild-type CT.

\section{Results}

\section{Alterations of Bax CT improve its binding to mitochondria but not necessary its killing efficiency}

Previous reports showed that C-terminal c-myc-tagged human Bax is very efficient in killing yeast, and that this death is accompanied by cytochrome $c$ release and is fully prevented by co-expression of $\mathrm{Bcl}-\mathrm{x}_{\mathrm{L}} \cdot{ }^{8,9,22,23}$

Since the introduction of a c-myc tag at the C-terminal end of Bax already represented a modification from the native protein, a new series of Bax variants was engineered on the basis of untagged human Bax. In the first variant, amino acids
173-192 of Bax were replaced by the homologous sequence of $\mathrm{Bcl}-\mathrm{x}_{\mathrm{L}}$ (variant $\mathrm{Bax} \mathrm{XL}$ ). In the second variant, they were replaced by a hydrophilic sequence designed to acquire a random coil structure (variant BaxRC) (Figure 1). Comparison of the C-terminal sequences (160-end) of variants Bax, Bax-c$m y c, B a x X L$ and BaxRC shows that the marked hydrophobic character of $\alpha 9$ is conserved in the BaxXL variant, but is compromised in variants BaxRC, which is essentially hydrophilic, as well as in Bax-c-myc, due to the hydrophilic tag (Figure 2).

It may be noted that, in addition to the hydrophobic character, $\mathrm{p} /$ of the $\mathrm{C}$-terminal end of the protein is changed by the modifications: $\mathrm{p} /$ of the C-terminus of $\mathrm{Bax}$ is 10.0 , because of the presence of two lysines in positions 189/190. This high $\mathrm{p} /$ is slightly decreased in BaxXL (8.8) and more strongly decreased in BaxRC (6.8) and Bax-c-myc (6.3). Consequently, at physiological $\mathrm{pH}$, the $\mathrm{C}$-terminal ends of Bax and $B a x X L$ are positively charged, whereas that of $B a x R C$ is neutral, and that of Bax-c-myc is slightly negative. It is also noteworthy that the variant $\operatorname{Bax} \Delta \mathrm{C}-c-m y c$, which exhibits a strong cytochrome $c$-release activity only partially reversed by the coexpression of $\mathrm{Bcl}-\mathrm{x}_{\mathrm{L}}$, has a C-terminal end (the c-myc tag) with a very low $\mathrm{pl}$ of 4.4 .

The variant proteins (BaxXL and BaxRC) as well as the native form of Bax were assayed for their ability to kill yeast, to insert in mitochondria and to release cytochrome $c$.

In contrast with Bax-c-myc, native human Bax was unable to kill yeast (Figure 3a). Replacement of $\alpha 9$-helix by that of $\mathrm{Bcl}$ $x_{L}$ did not significantly increase the killing efficiency, whereas replacement of $\alpha 9$-helix by a random coil sequence remarkably increased the cytotoxicity of BaxRC compared to native Bax.

According to its innocuousness, native Bax was absent from purified mitochondria after $6 \mathrm{~h}$ of expression, under

\begin{abstract}
Bax
MDGSGRQPRG GGPTSSRQIM KT GLLLLGP IODRAGRMGG BAPELLLDPV PQDASTKKLS BCLKRICDEL DSRMELRPI

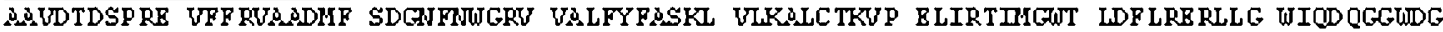
LLSTFGTP TW QTVTIFVACW LTASLTTWKK MAG
\end{abstract}

Baxc-mpe

IDGSGRQPRG GGPTSSBQIM KTGSLLLQGF IQDRAGRMGG ES.PBLALDPV PQDASTKKLS BCLKRICDEL DSMRLQRH B.SUDTDSPRE UFFRUASDMF SDGIFNGRV VALFYFSSKL VLKALCTKUP ELIRTDMGNT LDFLRBRLLG WIQDQGGUDG LLSYFGTPTW QTUTIFVAQV LTASLTTUKK MGSREQRTIS EEDLNG

$\operatorname{BaxXL}$

IDGSGBQPRG GGPTSSEOIM KTGSLLLQGF IODRAGRMG RSPELSLDPV PODASTKRLS BCLKRI CDEL DSRMELQRII

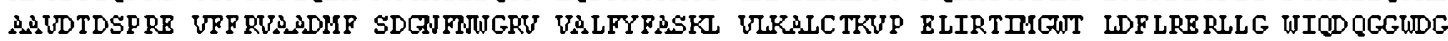
LLSYFGTPTW QIIULLTOMT VAGVVLLGSL LFSRK

BaxRC

MDGSGBQPRG GGPTSSRQIM KTGSLLLQGF IQDRAGRMGG ESPELALDPV PQDASTKRLS ECLKRICDEL DSMMLQRH

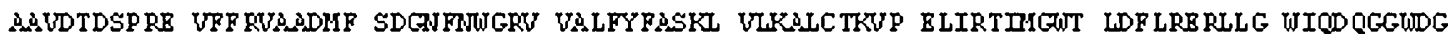
LLSTFGTP TW QIGLVRDGW CGRRGSAGLT LQSNISGRSS MULBGRIN

Figure 1 Primary structure of Bax variants. Deleted sequences in $\operatorname{Bax} \Delta N, B a x \Delta C$ and $B a x \Delta N \Delta C$ variants are underlined; $c$-myc tag is in bold; altered sequences in BaxXL and BaxRC are in italic 

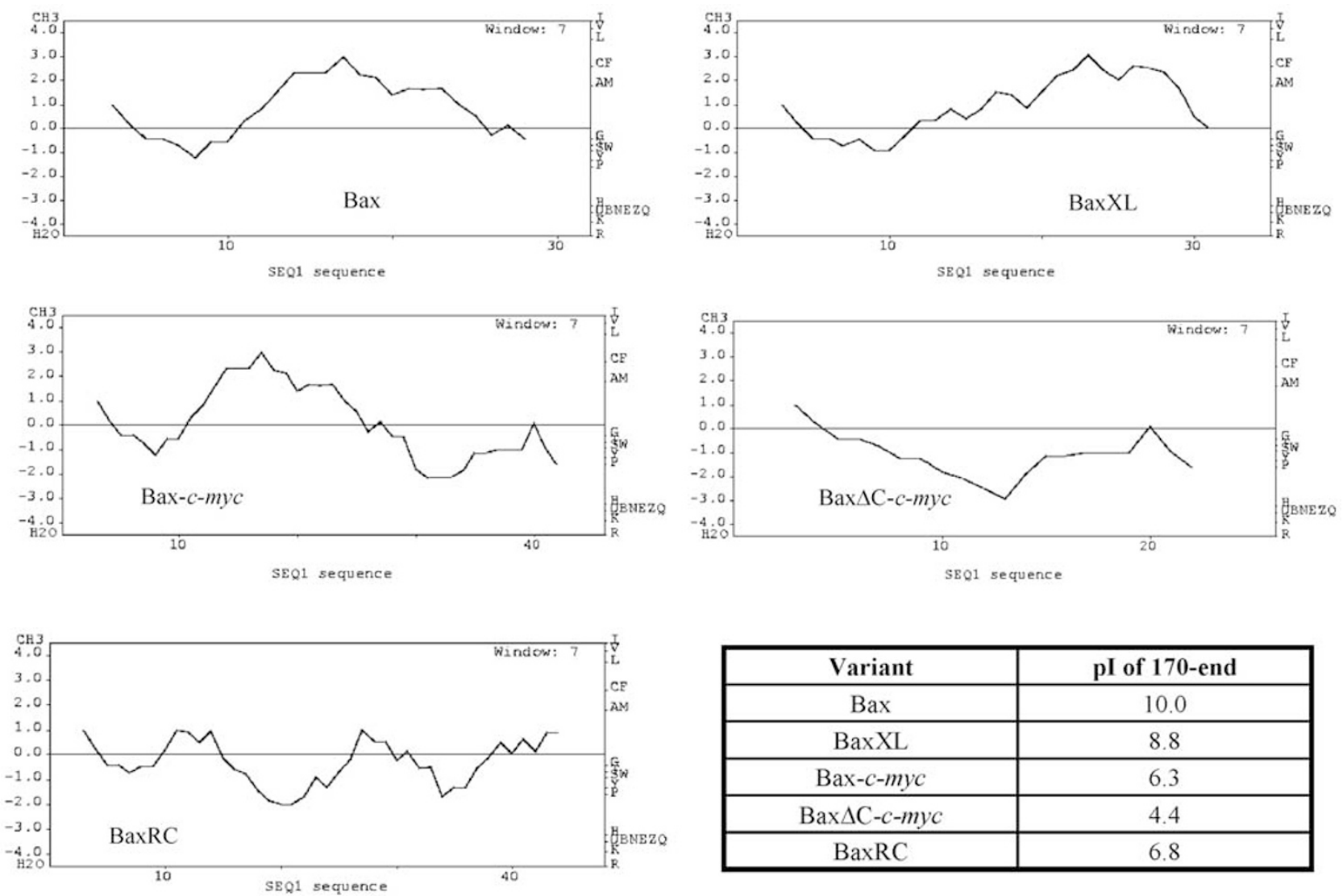

\begin{tabular}{|c|c|}
\hline Variant & pI of 170-end \\
\hline Bax & 10.0 \\
\hline BaxXL & 8.8 \\
\hline Bax-c-myc & 6.3 \\
\hline Bax $\Delta \mathrm{C}-c-m y c$ & 4.4 \\
\hline BaxRC & 6.8 \\
\hline
\end{tabular}

Figure 2 Structure analyses of the C-terminal ends of Bax variants. Kyte-Doolittle plots were generated on 160-end parts of the different variants with a seven aminoacid window using the FASTA program at the University of Virginia (http://fasta.bioch.virginia.edu/o_fasta/grease.htm) . p/values were calculated on 170-end parts of the variants using the $\mathrm{p} /$ tool at Swiss-Prot (http://www.expasy.org/tools/pi_tool.html)

conditions where both BaxXL and BaxRC exhibited a mitochondrial localization (Figure $3 b$ ).

In contrast to native Bax, BaxRC did have a significant effect on the release of cytochrome $c$ (Figure 3c). The lack of release induced by native Bax is in accordance with its absence from mitochondrial membrane. BaxXL only induced a marginal release of cytochrome $c$. This seems surprising, considering its presence in mitochondria, but correlates well with previous observations in mammalian cells, where BaxXL has a constitutive mitochondrial localization without any proapoptotic effect. ${ }^{24}$ This indicates that insertion of Bax into mitochondrial membrane is a necessary but insufficient step for its action.

Taken together, these data suggest that replacement of the C-terminus of Bax by a less hydrophobic sequence does not impair but, on the contrary, improves its capacity to bind to yeast mitochondria, to induce the release of cytochrome $c$, and to promote cell death. This is not the behaviour expected from a mitochondria-targeting/insertion sequence.

\section{Role of the interaction between $\mathrm{C}$ - and N-terminal ends of Bax}

Goping et al. ${ }^{16}$ reported that an N-truncated variant of Bax, deprived from the 20 first amino acids, was able to interact strongly with mitochondria. These observations were further confirmed by the fact that naturally occurring variants with similar characteristics exhibited strong proapoptotic activity ${ }^{17,18}$. Goping et al. ${ }^{17}$ proposed that the $\mathrm{N}$-terminal end of Bax prevented the interaction of the C-terminal anchoring sequence with mitochondrial membrane. In an attempt to verify this hypothesis, three new variants were engineered, lacking the $\mathrm{N}$-terminus end $(\operatorname{Bax} \Delta \mathrm{N})$, the C-terminus end $(\operatorname{Bax} \Delta \mathrm{C})$ or both ends $(\operatorname{Bax} \Delta \mathrm{N} \Delta \mathrm{C})$. The three mutants exhibited the same killing efficiency, higher than that of native Bax (Figure 4a), and also a high cytochrome $c$ releasing activity (Figure $4 \mathrm{C}$ ). Measurement of their interaction with mitochondria showed that both $\operatorname{Bax} \Delta \mathrm{N}$ and $\operatorname{Bax} \Delta \mathrm{C}$ mutants were strongly anchored in the mitochondrial outer membrane since they were not released by Triton X-100 (Figure 4b). The double-truncated mutant, however, was sensitive to Triton X-100 (like native Bax), but was present in mitochondria in similar amounts as $\operatorname{Bax} \Delta \mathrm{N}$ and $\operatorname{Bax} \Delta \mathrm{C}$ (and higher amounts than native Bax). Taken together, these data show that the double truncated mutant $\operatorname{Bax} \Delta N \Delta C$ is as efficient as $\operatorname{Bax} \Delta \mathrm{N}$ and $\operatorname{Bax} \Delta \mathrm{C}$ to promote the release of cytochrome $c$. This shows that, even when the $\mathrm{N}$-terminus is removed, the C-terminus is not required to allow the release of cytochrome $c$. This is an additional strong argument against an anchoring function of the C-terminus, whether or not the $\mathrm{N}$-terminus is present. 


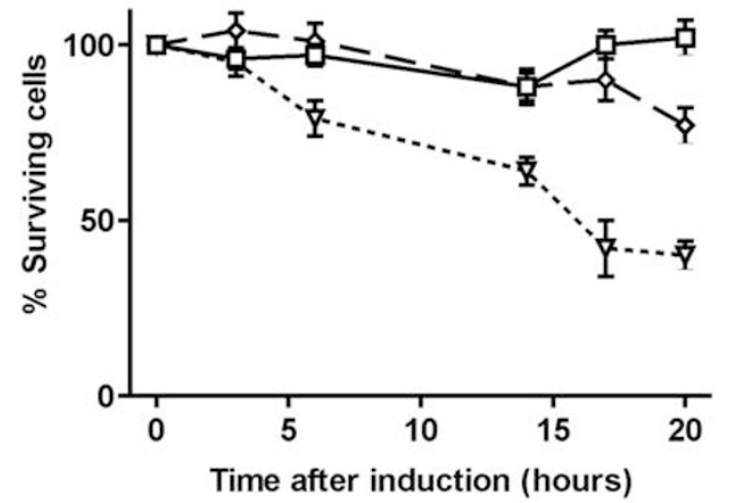

b

\section{bax baxXL baxRC}
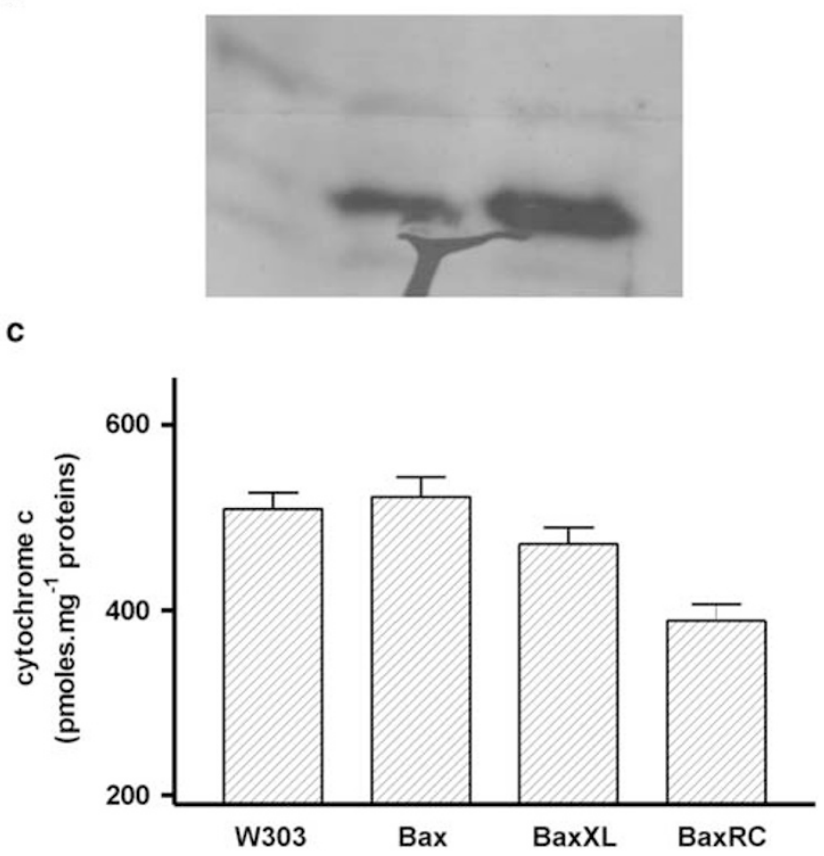

Figure 3 Comparison of native Bax, BaxXL and BaxRC. (a) Cell death induced by the expression of native $\operatorname{Bax}(\square)$, BaxXL $(\diamond)$ and $\operatorname{BaxRC}(\triangle)$. Cells were grown in lactate medium, and then transferred to a galactose medium. At indicated times, aliquots of 200 cells were spread on YPD plates and the number of growing colonies was counted after a 3-day incubation at $28^{\circ} \mathrm{C}$. (b) Western blots of mitochondrial proteins $(200 \mu \mathrm{g})$ with anti-Bax antibody N20 after $6 \mathrm{~h}$ of expression. (c) Cytochrome $c$ content of mitochondria isolated from the strains expressing the different variants after $6 \mathrm{~h}$ of expression

\section{Bid or tc-Bid-coexpression does not allow Bax to acquire an active conformation in yeast but tc-Bid stimulated the effect of an activated Bax variant}

According to Desagher and Martinou, ${ }^{5}$ Bid would help Bax to acquire its active conformation. We assayed its effect in yeast and therefore coexpressed full-length Bid and native Bax or Bax-c-myc. In the latter case, Bax-c-myc was expressed under the control of the weak promoter tet-off, in order to be able to observe a putative stimulating effect of Bid. Although full-length Bid was found to have some effects in mammalian mitochondria, the most active form of the protein is the

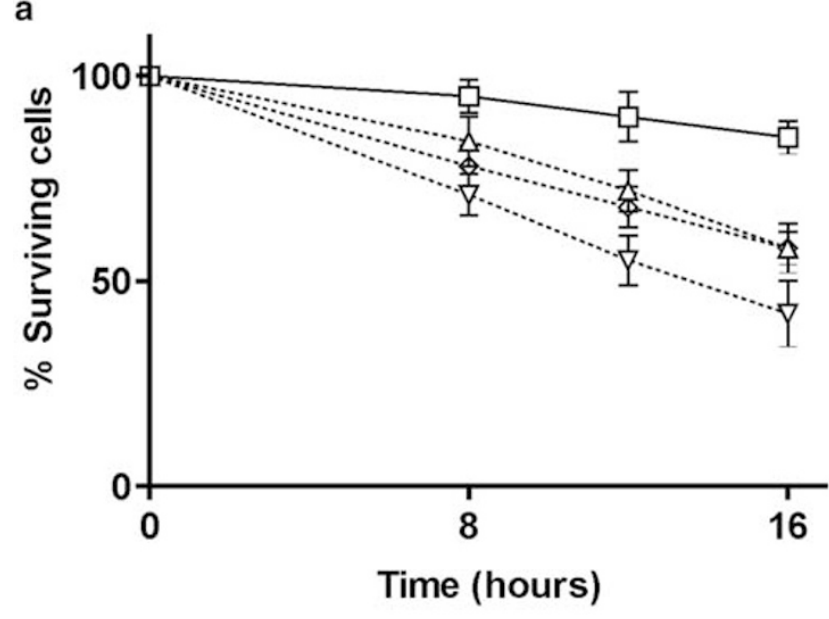

b

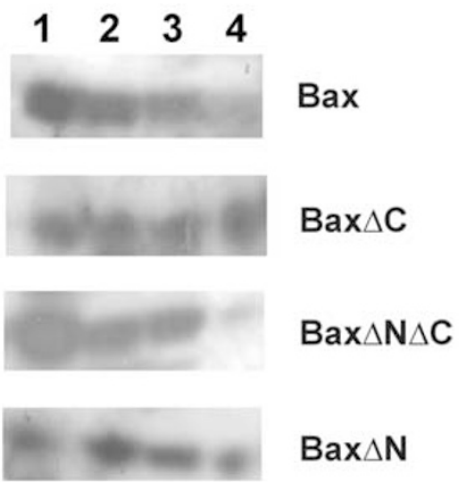

C

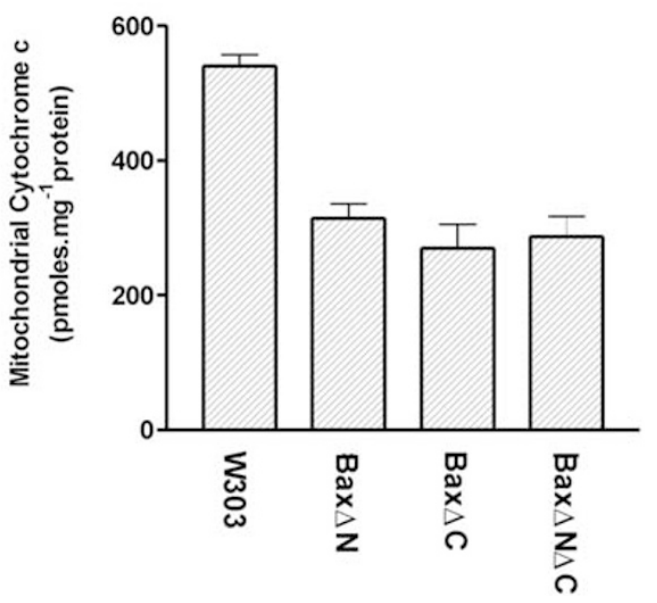

Figure 4 Comparison of $\operatorname{Bax} \Delta N, \operatorname{Bax} \Delta C$ and $\operatorname{Bax} \Delta N \Delta C$. (a) Cell death induced by the expression of native $\operatorname{Bax}(\square), \operatorname{Bax} \Delta \mathrm{N}$ (upward triangles), Bax $\Delta \mathrm{C}$ $(\nabla)$ or $\operatorname{Bax} \Delta \mathrm{N} \Delta \mathrm{C}(\diamond)$ was measured at the indicated times after galactose addition, as in Figure 3a. (b) Mitochondria were isolated from the different strains $6 \mathrm{~h}$ after galactose addition. Mitochondria $\left(1 \mathrm{mg} \mathrm{ml}^{-1}\right)$ were incubated for $10 \mathrm{~min}$ on ice in the absence (lane 1) or in the presence of $0.1 \mathrm{M} \mathrm{Na}_{2} \mathrm{CO}_{3}$ (lane 2), $0.1 \%$ Triton X-100 (lane 3) or 1\% Triton X-100 (lane 4), then centrifuged (15 min, $105000 \times g$ ) and proteins were separated on SDS-PAGE, transferred on PVDF membranes and blotted with anti-(murine)Bax $\Delta \mathrm{C} 21$ antibody. A measure of $800 \mu \mathrm{g}$ mitochondrial proteins was loaded with Bax, while $200 \mu \mathrm{g}$ were loaded with the three other variants (c) Cytochrome $c$ content of isolated mitochondria was measured after $6 \mathrm{~h}$ of expression, as in Figure $3 \mathrm{c}$ 

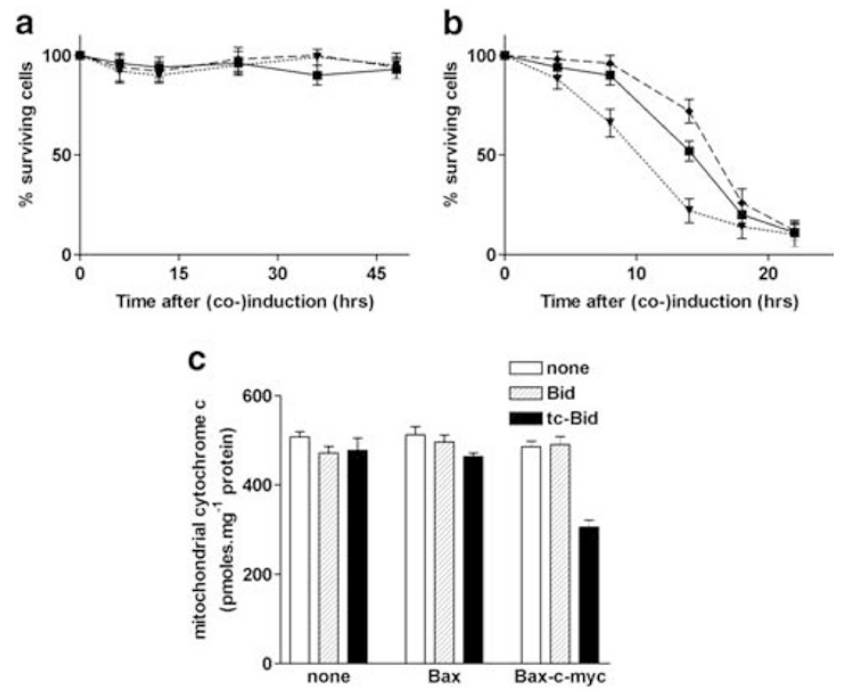

Figure 5 Effects of Bid and tc-Bid on Bax and Bax-c-myc-induced cell death. (a) W303/Bax (畐), W303/Bax/Bid ( ) and W303/Bax/tcBid ( $)$ strains were grown in lactate medium and then transferred to galactose medium. At different time, aliquots of 200 cells were spread on YPD plates and the number of growing colonies was counted after 3 days. (b) Wtb1, Wtb1/Bid and Wtb1/tcBid were grown in galactose medium in the presence of doxycyclin, then washed and transferred in the same medium without doxycyclin. At different times, aliquots of 200 cells were spread on YPD plates + doxycyclin and the number of growing colonies was countered after a 3-day-incubation at $28^{\circ} \mathrm{C}$. (c) Cytochrome $\mathrm{C}$ content was measured on isolated mitochondria after $8 \mathrm{~h}$ of (co)expression

caspase-8-generated $15 \mathrm{kDa}$ C-terminal fragment termed tcBid. ${ }^{25} \mathrm{~A}$ gene encoding this truncated form was then also built and tc-Bid protein was assayed in parallel to Bid.

From data reported in Figure $5 \mathrm{a}$, Bid and tc-Bid did not allow native Bax to acquire a killing effect in yeast. This shows that, when expressed in yeast, independently of the mammalian apoptotic network, Bid and tc-Bid are unable to induce the conformational change of Bax allowing its activation.

Bid and tc-Bid were therefore assayed on the kinetics of cell death induced by the activated form Bax-c-myc (Figure 5b). Bid did not have any stimulating effect; on the contrary, tc-Bid significantly stimulated the rate of Bax-c-myc-induced cell death.

This stimulation of Bax-c-myc effects by tc-Bid was even more obvious on the release of cytochrome $c$ (Figure $5 c$ ). Bid and tc-Bid alone or in combination with native Bax are not able to induce any release of cytochrome $c$, in accordance with the lack of effects on cell death. When expressed under the control of the weak promoter tet-off, Bax-c-myc is able to kill yeast (see Figure $5 \mathrm{~b}$ ), but this death happens without a significant release of cytochrome $c$ (Figure $5 c$; see also Priault et al. $^{26}$ and Roucou et $a .^{27}$ ). In accordance with the killing assays, Bid coexpression with Bax-c-myc did not induce any release of cytochrome $c$, while tc-Bid and Bax-c-myc coexpression induced a massive release of cytochrome $c$.

\section{Localization of Bid and tc-Bid in yeast cells and their effect on the localization of Bax-c-myc}

Although Bid is strongly expressed in yeast cells, it was hardly found in mitochondrial and microsomal membranes, but was a

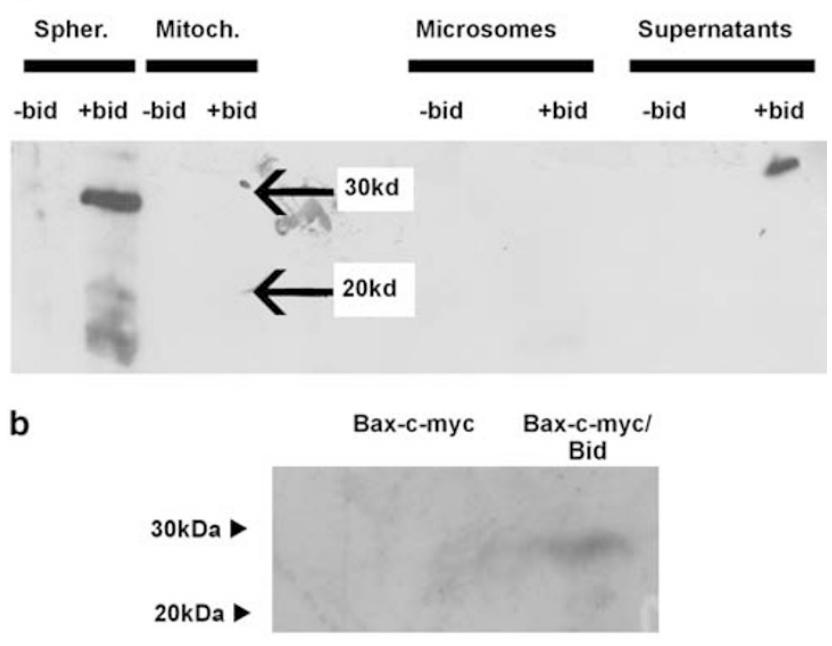

C

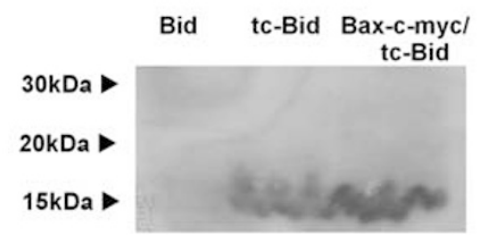

Figure 6 Localization of Bid and tc-Bid in yeast. (a) W303 (-bid) or W303/Bid (+ bid) spheroplasts (spher.) were fractionated to a mitochondria-enriched fraction (mitoch.), a microsomal fraction (microsomes) and a post-microsomal fraction (supernat.). A measure of $250 \mu \mathrm{g}$ proteins from each fraction was loaded in each lane. Bid was revealed with an anti-Bid antibody directed against the purified protein, ${ }^{19}$ which reveals native Bid at $28 \mathrm{kDa}$ and some degradation products below $20 \mathrm{kDa}$. (b) A measure of $800 \mu \mathrm{g}$ of mitochondrial proteins isolated from cells expressing Bax-c-myc alone or both Bax-c-myc and Bid was blotted with the anti-Bid antibody showing that Bid can be found at trace levels in the mitochondrial fraction. (c) A measure of $200 \mu \mathrm{g}$ of mitochondrial proteins from W303/Bid, W303/tcBid or Wtb1/tcBid was separated by SDS-PAGE and blotted with the anti-Bid antibody revealed by Western blot. At this amount of proteins, Bid cannot be detected in mitochondria, contrary to tcBid which appears as a $15 \mathrm{kDa}$ band. The presence of Bax-c-myc increases the amount of mitochondrial tc-Bid

mostly found in the cytosol (Figure 6a). However, trace amounts of Bid could be detected on blots made with concentrated mitochondrial proteins (Figure 6b), showing that Bid is marginally able to bind to yeast mitochondria. On the contrast, tc-Bid could be detected in purified mitochondria, under conditions where Bid was not (Figure 6c). Interestingly, the amount of mitochondrial tc-Bid was increased when it was coexpressed with the activated variant Bax-c-myc (Figure 6c).

Conversely, localization of Bax-c-myc was investigated, following its coexpression with tc-Bid. When expressed in yeast, activated variant Bax-c-myc is found in all fractions including the cytosol, microsomes and mitochondria (Figure 7a). It appears clearly that tc-Bid did not increase the amount of Bax-c-myclocalized in mitochondria (Figure $7 \mathrm{~b}$ ).

\section{Discussion}

Previous data were obtained on Bax variants carrying a Cterminal c-myc tag. Bax-c-myc was found to be highly efficient to kill yeast, ${ }^{8}$ to insert into mitochondrial membrane ${ }^{10,23}$ and 
a

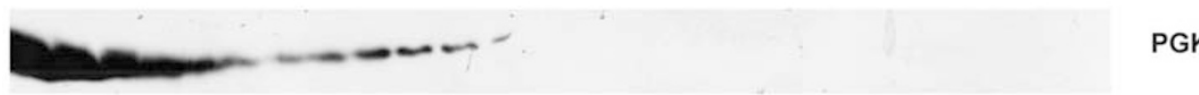

PGK

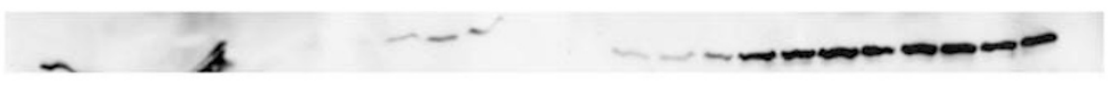

$\operatorname{cox} 2$

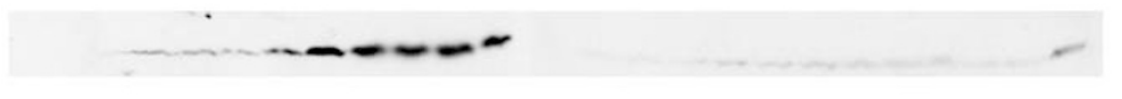

DPMS

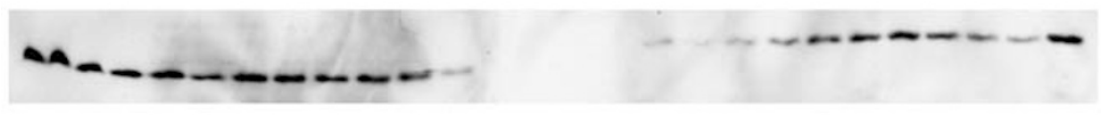

Bax

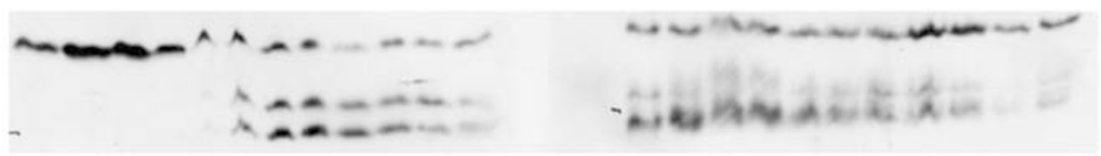

c-myc

b

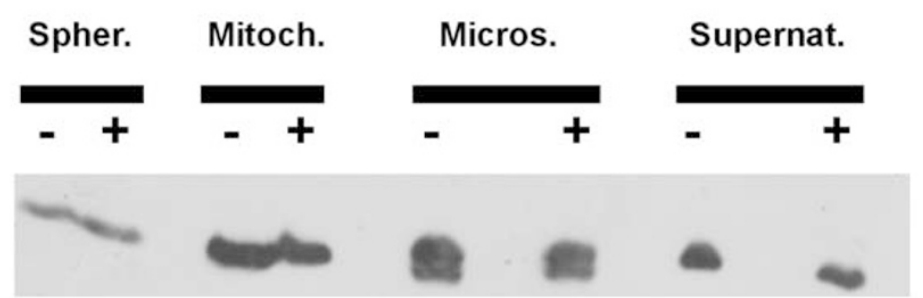

Figure 7 Effect of tcBid on Bax-c-myc localization. (a) Wtb1 cells were incubated for $14 \mathrm{~h}$ in the absence of doxycyclin (induction of Bax-c-myc) and spheroplasts were obtained by zymolyase treatment. Cells were homogenized and centrifuged for $20 \mathrm{~min}$ at $2.500 \times g$ to eliminate unbroken cell and cell debris. The supernatant was layered on the top of a $10 \mathrm{ml} 25-65 \%$ continuous sucrose gradient in $10 \mathrm{mM}$ potassium phosphate $(\mathrm{pH} 7.2)$ and centrifuged for $90 \mathrm{~min}$ at $105000 \times \mathrm{g}$. Fractions $(0.5 \mathrm{ml})$ were collected and proteins were recovered by TCA precipitation, separated on 12.5\% SDS-PAGE and blotted with anti-cox2 (cytochrome $c$ oxidase subunit 2; mitochondrial) anti-PGK (cytosolic) and anti-DPMS (reticulum) as well as anti-Bax and anti-c-myc-tag antibodies. The anti-tag antibody allows one to vizualize the Nterminally truncated forms at 18 and $15 \mathrm{kDa}$, which are spontaneously generated as the same time as membrane insertion, as already reported. ${ }^{10}$ Left to right is top to bottom. (b) Wtb1 (-) or Wtb1/tcBid $(+)$ cells were fractionated and Bax-c-myc was revealed with anti-BaxN20 antibody

to induce massive cytochrome $c$ release. ${ }^{22}$ As expected from specific effects related to proapoptotic activity of Bax, coexpression of antiapoptotic Bcl- $x_{\mathrm{L}}$ fully prevented all Baxinduced hallmarks. ${ }^{8,10,22,23}$

The absence of amino acids 173-192, containing the helix $\alpha 9$ of $\mathrm{Bax}^{7}$ did not change the ability of the c-myc-tagged protein to kill yeast. $^{9,10}$ Furthermore, C-terminal-truncated $\operatorname{Bax} \Delta \mathrm{C}-\mathrm{c}-m y c$ did insert in mitochondrial membrane and was able to release cytochrome $c$ with the same efficiency as fulllength Bax-c-myc. ${ }^{10}$ Interestingly, the protective effect of Bcl$\mathrm{X}_{\mathrm{L}}$ co-expression was modified: $\mathrm{Bcl}-\mathrm{X}_{\mathrm{L}}$ only partially protected yeast against the killing effect of $\operatorname{Bax} \Delta \mathrm{C}-c-m y c^{9}$ and, accordingly, did not fully prevent cytochrome $c$ release induced by Bax $\Delta \mathrm{C}-\mathrm{c}-m y c .^{10} \mathrm{~A}$ truncated form of $\mathrm{Bcl}-\mathrm{x}_{\mathrm{L}}$, lacking amino acids 204-233, was less efficient than fulllength $\mathrm{Bcl}-\mathrm{x}_{\mathrm{L}}$ in protecting yeast against the effects of Bax-c$m y c,{ }^{9,10}$ in accordance with previous reports showing an absolute requirement of the $\mathrm{C}$-terminal $\alpha$-helix of $\mathrm{Bcl}-\mathrm{x}_{\mathrm{L}}$ for its insertion into mitochondrial membrane. ${ }^{8}$ The effects of the Cterminally truncated $\mathrm{Bax} \Delta \mathrm{C}-\mathrm{c}-m y c$ variant were not prevented by $\mathrm{Bcl}-\mathrm{x}_{\mathrm{L}}$ nor, obviously, by Bcl- $\mathrm{x}_{\mathrm{L}} \Delta \mathrm{C}$.

Since the C-terminal $\alpha$-helix of antiapoptotic proteins such as $\mathrm{Bcl}-2$ or $\mathrm{Bcl}-\mathrm{x}_{\mathrm{L}}$ was shown to be responsible for their targeting to mitochondria, the same function was attributed to the C-terminal end of proapoptotic Bax. Data reported in this paper go against this hypothesis since modification or even suppression of $\mathrm{Bax} \alpha 9$-helix has a positive effect on the interaction of the protein with mitochondria. On the contrary, these data support the hypothesis that, in its native conformation, the $\alpha 9$ helix prevents Bax/mitochondria interaction.

On the one hand, and as expected, the replacement of Bax $\alpha 9$-helix by the homologous sequence of $\mathrm{Bcl}-\mathrm{x}_{\mathrm{L}}$, which was actually shown to be a membrane anchor, allows the docking of the chimeric protein BaxXL. This confirms previous data obtained with this variant in mammalian mitochondria. ${ }^{24}$ 
However, the hybrid protein does not acquire proapoptotic activity in mammalian cells and, as expected, does not induce a massive release of cytochrome $c$, nor any killing effect in yeast. This clearly shows that anchoring of Bax in mitochondria is not enough to activate the protein.

It should be noted that, once inserted in the membrane, alterations of the $\mathrm{C}$-terminal end of Bax have various effects on the function of the protein. The least perturbing modification is the addition of a c-myc tag: Bax-induced mitochondrial apoptosis-induced channel (MAC) is likely responsible for cytochrome $c$ release in yeast, and its electrophysiological properties are indistinguishable, whether formed by native Bax in mammalian cells or Bax-c-myc in yeast cells. ${ }^{28}$ Suppression of the $\alpha 9$ helix does not have any direct consequences on Bax functions per se, but seems to alter further interaction with antiapoptotic $\mathrm{Bcl}-\mathrm{x}_{\mathrm{L}}$, at least in yeast. ${ }^{910}$ Quite surprisingly, the most perturbating modification is the replacement of $\operatorname{Bax} \alpha 9$ helix by that of $\mathrm{Bcl}-\mathrm{x}_{\mathrm{L}}$, which confers only marginal activity in yeast (this paper) and fully impairs proapoptotic function in mammalian cells. ${ }^{24}$ This indicates that unregulated addressing provided by the $\mathrm{Bcl}-\mathrm{x}_{\mathrm{L}}$ anchoring sequence does not allow Bax to acquire a fully active conformation.

Which intrinsic properties could be responsible for the conformational change of the C-terminal $\alpha 9$ helix? The comparison of inactive (Bax and BaxXL) and active (Bax-c$m y c, \operatorname{BaxRC}, \operatorname{Bax} \Delta \mathrm{C}, \operatorname{Bax} \Delta \mathrm{C}-\mathrm{c}-m y c)$ variants suggests that the hydrophobic character, and also possibly the global charge, of the C-terminal end may play a role: a high hydrophobia as well as a positive charge are associated with an absence of activity. This is a functional confirmation of data gained from Bax structure determined by $\mathrm{NMR}^{7}{ }^{7}$ showing that the C-terminal end of inactive Bax (i.e. cytosolic conformation) lies in a hydrophobic pocket. Destabilization of the interaction between $\mathrm{C}$-terminus and the hydrophobic zone is probably a prerequisite for the interaction of Bax with mitochondria. ${ }^{7}$ However, from data reported in the present paper, it would not be itself the membrane-interacting zone.

It has been demonstrated that deletion of the $\mathrm{N}$-terminal end domain of Bax improved its addressing into membranes, and it was proposed that the C-terminal end, considered as the membrane anchor, was protected from membrane interaction by the $\mathrm{N}$-terminus. ${ }^{16}$ Data reported herein show that the $\mathrm{C}$-terminal end of Bax is not a membrane anchor, even in the absence of the $\mathrm{N}$-terminus, since the doubletruncated variant still exhibits strong activity. Recent data suggest that, once the $\mathrm{N}$-terminal domain is removed, the mitochondria addressing sequence might lie at the level of the $\alpha 1$ helix. ${ }^{29}$ In this hypothesis, the C-terminal end of Bax would prevent the interaction of $\alpha 1$ with membranes, by interacting with the $\mathrm{N}$-terminal end.

This raises the question of what is physiologically responsible for the conformational change of the C-terminal end? Bid, and more precisely its caspase-8-generated activated form tc-Bid, has been proposed to be critical for Bax activation, from experiments conducted on isolated mitochondria. ${ }^{20}$ Yeast provides a neutral cellular model to assay a possible effect of (tc-)Bid on Bax/mitochondria interaction. Clearly, Bid and tc-Bid did not allow the activation of native Bax in yeast, demonstrating that (tc-)Bid/Bax interaction is not enough to activate Bax. On the other hand, tc-Bid (but not fulllength Bid) increased the effect of an already activated variant of Bax. This effect was not related to any stimulation of localization and insertion of Bax-c-myc in mitochondrial membranes. This suggests that the conformational change of the C-terminal end of Bax and further addressing/insertion in the mitochondrial outer membrane occurs (and is a prerequisite) before tc-Bid plays any part; the role of tc-Bid thus seems to be restricted to later steps of Bax-activation, namely the oligomerization process. ${ }^{21,30}$ Actually, it has been demonstrated that Bid was able to induce the formation of a cytochrome $c$-permeable channel from Bax. ${ }^{30}$ It should be noted that all the experiments in yeast demonstrate that tc-Bid is not mandatory for this process, since Bax variants are active in the absence of tc-Bid: tc-Bid may thus only stimulate an otherwise slow process.

A working model for Bax translocation to mitochondria can be drawn from these results (Figure 8). Cytosolic Bax would support a conformational change that is mimicked by alterations of the $\alpha 9$ helix or the $\mathrm{N}$-terminus. Activated Bax can then be inserted into the mitochondrial outer membrane. A second membrane step is the oligomerization of Bax, which would depend on tc-Bid, as well as on another still-unidentified mitochondrial protein, ${ }^{21}$ leading to the formation of a large channel (MAC) able to translocate cytochrome from intermembrane space to the cytosol. ${ }^{28}$ It should be noted that recent data obtained on heart mitochondria support the idea that both full-length Bax and C-terminally truncated Bax, are able to permeabilize the outer mitochondrial membrane to cytochrome, without any effect on the permeability of the inner mitochondrial membrane. ${ }^{31}$

How would tc-Bid act? The fact that Bax-c-myc stimulates the membrane insertion of tc-Bid (Figure 6) suggests a direct interaction between both proteins, such as the formation of a heterodimer. But, since tc-Bid does not stimulate the membrane insertion of Bax-c-myc, it is likely that the

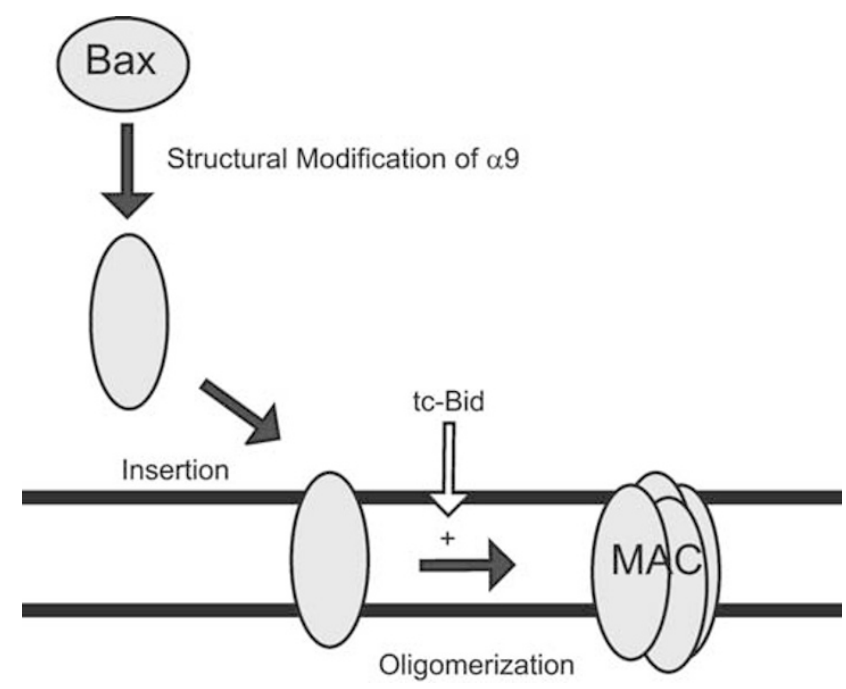

Figure 8 The different steps of Bax-activation. Native Bax supports a conformational change that can be mimicked by the alteration of the $\mathrm{C}$-terminal end, allowing the insertion of the protein into the outer mitochondrial membrane; tc-Bid does not interfere at these steps. The further oligomerization that allows one to acquire the channel activity is a late step and can be stimulated by tc-Bid 
Table 1 Strains used in this study

\begin{tabular}{|c|c|c|}
\hline Strain & Genotype & Phenotype \\
\hline W303-1A & Mat a, ade1, his3, leu2, trp1, ura3 & Wild-type \\
\hline \multirow{2}{*}{ W303/Bid } & Mat a, ade1, his3, leu2, trp1, ura3 & \\
\hline & pYES3/Bid (TRP1) & Expression of Bid (GAL1 promoter) \\
\hline \multirow[t]{2}{*}{ W303/tcBid } & Mat a, ade1, his3, leu2, trp1, ura3 & \\
\hline & pYES3/tcBid (TRP1) & Expression of Bid (GAL1 promoter) \\
\hline \multirow[t]{2}{*}{ Wtb1 } & Mat a, ade1, his3, leu2, trp1, ura3 & \\
\hline & pCM189/Bax-c-myc (URA3) & Expression of Bax-c-myc (tet-off promoter) \\
\hline \multirow[t]{3}{*}{ Wtb1/Bid } & Mat a, ade1, his3, leu2, trp1, ura3 & \\
\hline & pCM189/Bax-c-myc (URA3) & Expression of Bax-c-myc (tet-off promoter) \\
\hline & pYES3/Bid (TRPI) & Expression of Bid (GAL1 promoter) \\
\hline \multirow[t]{3}{*}{ Wtb1/tc-Bid } & Mat a, ade1, his3, leu2, trp1, ura3 & \\
\hline & pCM189/Bax-c-myc (URA3) & Expression of Bax-c-myc (tet-off promoter) \\
\hline & pYES3/tc-Bid (TRP1) & Expression of tc-Bid (GAL1 promoter) \\
\hline \multirow[t]{2}{*}{ W303/Bax } & Mat a, ade1, his3, leu2, trp1, ura3 & \\
\hline & pYES2/Bax (URA3) & Expression of Bax (GAL1 promoter) \\
\hline \multirow[t]{3}{*}{ W303/Bax/Bid } & Mat a, ade1, his3, leu2, trp1, ura3 & \\
\hline & pYES2/Bax (URA3) & Expression of Bax (GAL1 promoter) \\
\hline & pYES3/Bid (TRP1) & Expression of Bid (GAL1 promoter) \\
\hline \multirow[t]{3}{*}{ W303/Bax/tcBid } & Mat a, ade1, his3, leu2, trp1, ura3 & \\
\hline & pYES2/Bax (URA3) & Expression of Bax (GAL1 promoter) \\
\hline & pYES3/tcBid (TRP1) & Expression of tcBid (GAL1 promoter) \\
\hline \multirow[t]{2}{*}{ W303/Bax $\Delta \mathrm{C}$} & Mat a, ade1, his3, leu2, trp1, ura3 & \\
\hline & pYES2/Bax $\triangle \mathrm{C}(U R A 3)$ & Expression of $\operatorname{Bax} \Delta \mathrm{C}$ (GAL1 promoter) \\
\hline \multirow[t]{2}{*}{ W303/BaxXL } & Mat a, ade1, his3, leu2, trp1, ura3 & \\
\hline & pYES2/BaxXL (URA3) & Expression of BaxXL (GAL1 promoter) \\
\hline \multirow[t]{2}{*}{ W303/BaxRC } & Mat a, ade1, his3, leu2, trp1, ura3 & \\
\hline & pYES2/BaxRC (URA3) & Expression of BaxRC (GAL1 promoter) \\
\hline \multirow[t]{2}{*}{ W303/Bax $\Delta \mathrm{N}$} & Mat a, ade1, his3, leu2, trp1, ura3 & \\
\hline & pYES2/Bax $\Delta \mathrm{N}(U R A 3)$ & Expression of $\mathrm{Bax} \Delta \mathrm{N}$ (GAL1 promoter) \\
\hline \multirow[t]{2}{*}{ W303/Bax $\Delta \mathrm{N} \Delta \mathrm{C}$} & Mat a, ade1, his3, leu2, trp1, ura3 & \\
\hline & $\mathrm{pYES} 2 / \mathrm{Bax} \Delta \mathrm{N} \Delta \mathrm{C}(U R A 3)$ & Expression of $\operatorname{Bax} \Delta \mathrm{N} \Delta \mathrm{C}$ (GAL1 promoter) \\
\hline
\end{tabular}

interaction occurs after Bax-c-myc is inserted. Also, the acquisition of an active form by Bax is not a spontaneous consequence of insertion, since membrane insertion is not always accompanied by full activation, as shown with the BaxXL variant. Recent data reported by Roucou et al. ${ }^{21}$ show the requirement of at least a third partner. Obviously, this partner would be present in yeast, since Bax-c-myc (as well as BaxRC, which is able to translocate cytochrome $c$ ) can be activated to a channel, even in the absence of tc-Bid. Thus, the use of yeast as a neutral cellular model for the expression of Bax variants (as well as other Bcl-2 family members) together with the use of yeast mutants altered in candidate mitochondrial proteins still represents a powerful tool to identify the molecular steps underlying the whole process.

\section{Experimental procedures}

Strains used in this study are listed in Table 1. The sequences of the different variants of Bax are listed in Figure 1. The construction of strains expressing Bax-c-myc and Bax $\Delta \mathrm{C}-\mathrm{c}$ $m y c$ has been described previously. ${ }^{8,26}$ Untagged Bax, BaxXL and BaxRC variants were amplified by PCR from plasmid $\mathrm{pRcCMV} / \mathrm{bax}^{13}$ and $\operatorname{Bax} \Delta \mathrm{N}, \operatorname{Bax} \Delta \mathrm{C}$ and $\operatorname{Bax} \Delta \mathrm{N} \Delta \mathrm{C}$ were amplified from plasmid pCM189/Bax-c-myc. ${ }^{26}$ All fragments were cloned between EcoR1 and Pme1 sites of pYES2 plasmid (Invitrogen). Bid and tc-Bid were amplified by PCR from plasmid pet23D/His-Bid ${ }^{20}$ and cloned between EcoR1 and Pme1 sites of pYES3/CT plasmid.

For the expression of Bax variants under the control of tet-off promoter, cells were grown aerobically in YNB medium $(0.17 \%$ yeast nitrogen base, $0.5 \%$ ammonium sulphate, $0.1 \%$ potassium phosphate, $0.2 \%$ Drop-Mix, $2 \%$ lactate or $2 \%$ galactose as a carbon source, $\mathrm{pH} 5.5$ ) in the presence of $10 \mu \mathrm{g} / \mathrm{ml}$ doxycyclin. Induction was achieved by washing the cells three times and resuspending in the same medium without doxycyclin.

For the expression of Bax variants under the control of GAL1/10 promoter, cells were grown aerobically in YNB medium supplemented with lactate. Induction was achieved by adding $0.8 \%$ galactose. For the coexpression of Bid (or tc-Bid) with Bax-c-myc, cells were grown in YNB medium supplemented with $2 \%$ galactose (allowing bid or tc-bid expression) in the presence of doxycyclin (preventing the expression of Bax-c-myc), and then washed and resuspended in the absence of doxycyclin (allowing the expression of Bax-c-myc). 
Cell death was measured by spreading 200 cells on complete glucose medium (YPD: yeast extract 1\%, BactoPeptone $1 \%$, glucose $2 \%, \mathrm{pH} 5.5$, added with doxycyclin $10 \mu \mathrm{g} / \mathrm{ml}$ if required) to repress the expression of Bax variants. Cells able to form colonies were counted after a 3-day incubation at $28^{\circ} \mathrm{C}$.

Cell fractionation was carried out on zymolyase-digested cells. ${ }^{22}$ After homogenization, a series of low-speed/highspeed centrifugations allowed to separate a mitochondriaenriched fraction, a microsomal fraction (pellet $105000 \times g$ ) and a post-microsomal fraction (supernatant $105000 \times g$ ). ${ }^{10}$ Separation of subcellular fractions on $25-65 \%$ continuous sucrose gradient was also performed (see the legend to Figure 7). Characterization of the fractions was carried out with antibodies directed against cytochrome oxidase subunit 2, dolichol-phosphate-mannose synthase (DPMS) and phosphoglycerate kinase (PGK), respectively (monoclonal mouse antibodies, Molecular Probes).

Assessment of the interaction of Bax variants with mitochondria was performed by treating mitochondria with $0.1 \mathrm{M} \mathrm{Na}_{2} \mathrm{CO}_{3}$, or $0.1 \%$ or $1 \%$ Triton $\mathrm{X}-100$ for $10 \mathrm{~min}$ on ice before sodium dodecyl sulphate-polyacrylamide gel electrophoresis (SDS-PAGE) separation and Western-blot analysis.

Western blots were done on protein separated on SDSPAGE and transferred onto polyvinyl difluoride PVDF membrane (Problott, Perkin-Elmer). Polyclonal anti-human Bax antibody (N20, Santa Cruz), polyclonal anti-murine Bax antibody ( $\Delta \mathrm{C} 21$, Santa Cruz), monoclonal anti-c-myc tag (Santa Cruz) and polyclonal anti-human Bid antibody (directed against the purified recombinant protein ${ }^{19}$ ) were further revealed with secondary anti-rabbit IgG antibody-peroxidase (Jackson Laboratories) and chemiluminescence (ECL + , Amersham).

Cytochrome c content was measured on isolated mitochondria. Mitochondrial suspensions $(5 \mathrm{mg} / \mathrm{ml})$ were dispatched in the two cuvettes of a double-beam spectrophotometer (Aminco DW2000). The reference cuvette was oxidized with potassium ferricyanide and the sample cuvette was reduced with sodium dithionite. Difference spectra were acquired between 500 and $650 \mathrm{~nm}$ to obtain complete spectra of all the cytochromes, thus allowing comparison with unreleased cytochrome $b$ and $a+a_{3}$. Cytochrome $c$ amount was calculated by measuring the absorbance difference between 550 and $540 \mathrm{~nm}\left(\Delta \varepsilon=18.000 \mathrm{M}^{-1} \mathrm{~cm}^{-1}\right)$.

\section{Acknowledgements}

This work was supported by grants from the Centre National de la Recherche Scientifique, the Association pour la Recherche contre le Cancer, the Conseil Régional d'Aquitaine and the Université de Bordeaux 2. MP was the recipient of a fellowship from the Ministère de la Recherche et de la Technologie.

\section{References}

1. Gross A, McDonnell JM and Korsmeyer SJ (1999) BCL-2 family members and the mitochondria in apoptosis. Genes Dev. 13: 1899-1911

2. Martinou JC and Green DR (2001) Breaking the mitochondrial barrier. Nat. Rev. Mol. Cell. Biol. 2: 63-67

3. Antonsson B and Martinou JC (2000) The Bcl-2 protein family. Exp. Cell Res. 256: $50-57$
4. Wolter KG, Hsu YT, Smith CL, Nechushtan A, Xi XG and Youle RJ (1997) Movement of Bax from the cytosol to mitochondria during apoptosis. J. Cell Biol. 139: 1281-1292

5. Desagher S and Martinou JC (2001) Mitochondria as the central control point of apoptosis. Trends Cell. Biol. 10: 369-377

6. Roucou $X$ and Martinou JC (2001) Conformational change of Bax: a question of life or death. Cell Death Diff. 8: 875-877

7. Suzuki M, Youle RJ and Tjandra N (2000) Structure of Bax: coregulation of dimer formation and intracellular localization. Cell 103: 645-654

8. Greenhalf W, Stephan C and Chaudhuri B (1996) Role of mitochondria and Cterminal membrane anchor of Bcl-2 in Bax induced growth arrest and mortality in Saccharomyces cerevisiae. FEBS Lett. 380: 169-175

9. Clow A, Greenhalf W and Chaudhuri B (1998) Under respiratory growth conditions, $\mathrm{Bcl}-\mathrm{x}(\mathrm{L})$ and $\mathrm{Bcl}-2$ are unable to overcome yeast cell death triggered by a mutant Bax protein lacking the membrane anchor. Eur. J. Biochem. 258: $19-28$

10. Priault M, Camougrand N, Chaudhuri B and Manon S (1999) Role of the $\mathrm{C}$-terminal domain of $\mathrm{Bax}$ and $\mathrm{Bcl}-\mathrm{XL}$ in their localization and function in yeast cells. FEBS Lett. 443: 225-228

11. Nguyen M, Millar DG, Yong VW, Korsmeyer SJ and Shore GC (1993) Targeting of $\mathrm{Bcl}-2$ to the mitochondrial outer membrane by a $\mathrm{COOH}$-terminal signal anchor sequence. J. Biol. Chem. 268: 25265-25268

12. Janiak F, Leber B and Andrews DW (1994) Assembly of Bcl-2 into microsomal and outer mitochondrial membranes. J. Biol. Chem. 269: 9842-9849

13. Tremblais K, Oliver L, Juin P, Le Cabellec MT, Meflah K and Vallette FM (1999) The C-terminus of bax is not a membrane addressing/anchoring signal. Biochem. Biophys. Res. Commun. 260: 582-591

14. Nechushtan A, Smith CL, Hsu YT and Youle RJ (1999) Conformation of the Bax C-terminus regulates subcellular location and cell death. EMBO J. 18: 2330-2341

15. Martinez-Senac M, Corbalan-Garcia S and Gomez-Fernandez JC (2001) Conformation of the $\mathrm{C}$-terminal domain of the pro-apoptotic protein Bax and mutants and its interaction with membranes. Biochemistry 40: 9983-9992

16. Goping IS, Gross A, Lavoie JN, Nguyen M, Jemmerson R, Roth K, Korsmeyer SJ and Shore GC (1998) Regulated targeting of BAX to mitochondria. J. Cell Biol. 143: 207-215

17. Wood DE and Newcomb EW (2000) Cleavage of Bax enhances its cell death function. Exp. Cell Res. 256: 375-382

18. Cartron PF, Moreau C, Oliver L, Mayat E, Meflah K and Vallette FM (2002) Involvement of the $\mathrm{N}$-terminus of $\mathrm{Bax}$ in its intracellular localization and function. FEBS Lett. 512: 95-100

19. Desagher S, Osen-Sand A, Nichols A, Eskes R, Montessuit S, Lauper S, Maundrell K, Antonsson B and Martinou JC (1999) Bid-induced conformational change of Bax is responsible for mitochondrial cytochrome $c$ release during apoptosis. J. Cell Biol. 144: 891-901

20. Eskes R, Desagher S, Antonsson B and Martinou JC (2000) Bid induces the oligomerization and insertion of Bax into the outer mitochondrial membrane. Mol. Cell. Biol. 20: 929-935

21. Roucou X, Montessuit S, Antonsson B and Martinou JC (2002) Bax oligomerization in mitochondrial membranes requires $\mathrm{tBid}$ and a mitochondrial protein. Biochem. J. 368: 915-921

22. Manon S, Chaudhuri B and Guérin M (1997) Release of cytochrome $c$ and decrease of cytochrome $C$ oxidase in Bax-expressing yeast cells, and prevention of these effects by coexpression of Bcl-xL. FEBS Lett. 415: 29-32

23. Priault M, Chaudhuri B, Clow A, Camougrand N and Manon S (1999) Investigation of bax-induced release of cytochrome $c$ from yeast mitochondria permeability of mitochondrial membranes, role of VDAC and ATP requirement. Eur. J. Biochem. 260: 684-691

24. Oliver L, Priault M, Tremblais K, Le Cabellec MT, Meflah K, Manon S and Vallette FM (2000) The substitution of the C-terminus of bax by that of bcl-xL does not affect its subcellular localization but abrogates its pro-apoptotic properties. FEBS Lett. 487: 161-165

25. Li H, Zhu H, Xu CJ and Yuan J (1998) Cleavage of BID by caspase 8 mediates the mitochondrial damage in the Fas pathway of apoptosis. Cell 94: 491-501

26. Priault M, Camougrand N, Chaudhuri B, Schaeffer J and Manon S (1999) Comparison of the effects of bax-expression in yeast under fermentative and respiratory conditions: investigation of the role of adenine nucleotides carrier and cytochrome c. FEBS Lett. 456: 232-238 
27. Roucou X, Prescott M, Devenish RJ and Nagley P (2000) A cytochrome c-GFP fusion is not released from mitochondria into the cytoplasm upon expression of Bax in yeast cells. FEBS Lett. 471: 235-239

28. Pavlov EV, Priault M, Pietkiewicz D, Cheng EHY, Antonsson B, Manon S, Korsmeyer SJ, Mannella CA and Kinnally KW (2001) A novel, high conductance channel of mitochondria linked to apoptosis in mammalian cells and Bax expression in yeast. J. Cell Biol. 155: 725-731

29. Cartron PF, Priault M, Oliver L, Meflah K, Manon S and Vallette FM (2003) The $\mathrm{N}$-terminal end of bax contains a mitochondrial-targeting signal. J. Biol. Chem. 278: 11633-11641
30. Roucou X, Rostovtseva T, Montessuit S, Martinou JC and Antonsson B (2002) Bid induces cytochrome $c$-impermeable Bax channels in liposomes. Biochem. J. 363: $547-552$

31. Appaix F, Guerrero K, Rampal D, Izikki M, Kaambre T, Sikk P, Brdiczka D, Riva-Lavieille C, Olivares J, Longuet M, Antonsson B and Saks VA (2002) Bax and heart mitochondria: uncoupling and inhibition of respiration without permeability transition. Biochim. Biophys. Acta 1556: 155-167 